\title{
Groundwater Quality in the Southern Sierra Nevada, California
}

Groundwater provides more than 40 percent of California's drinking water. To protect this vital resource, the State of California created the Groundwater Ambient Monitoring and Assessment (GAMA) Program. The Priority Basin Project of the GAMA Program provides a comprehensive assessment of the State's groundwater quality and increases public access to groundwater-quality information. The Tehachapi-Cummings Valley and Kern River Valley basins and surrounding watersheds in the Southern Sierra Nevada constitute one of the study units being evaluated.

\section{The Southern Sierra Nevada Study Unit}

The Southern Sierra Nevada study unit is approximately 1,800 square miles; it includes six groundwater basins (California Department of Water Resources, 2003) and parts of the hard-rock watersheds surrounding the basins (Fram and Belitz, 2007). The primary aquifers in the Tehachapi-Cummings Valley basins in the southern part of the study unit consist of alluvial fan and floodplain sediments (mixtures of sand, silt, clay, gravel, cobbles, and boulders). The primary aquifers in the Kern River Valley basin in the northern part of the study unit are composed of fluvial sediments from the Kern River. Outside of and beneath the basins, the primary aquifers are fractured granitic and metamorphic rocks.

The primary aquifers in the study unit are defined as those parts of the aquifers corresponding to the screened or open intervals of wells listed in the California Department of Public Health database. In the Tehachapi-Cummings basins, these wells typically are drilled to depths between 300 and 500 feet, consist of solid casing from land surface to a depth of about 100 to 225 feet, and are screened or open below the solid casing. In the Kern River Valley basin, these wells typically are 50 to 175 feet deep, and are screened or open below 25 to 100 feet. Water quality in the shallower and deeper parts of the aquifer system may differ from that in the primary aquifers. The areas outside of the basins have both wells and developed springs.

The Southern Sierra Nevada study unit has warm, dry summers and cold, wet winters. Average annual precipitation ranges from about 11 inches in the basins to over 50 inches in the surrounding mountains, and the majority of precipitation falls as snow. Land use in the Southern Sierra Nevada study unit is approximately 90 percent (\%) undeveloped (grasslands and scrublands), $8 \%$ cultivated agriculture, and $2 \%$ urban. The undeveloped lands are used mostly for recreation and openrange grazing. The largest urban areas are the city of Tehachapi and the small towns surrounding Lake Isabella.

Recharge to the groundwater flow system is mainly from mountainfront recharge at the margins of the basins, stream-channel infiltration, and direct infiltration of precipitation. Groundwater leaves the aquifer system mainly as pumpage for irrigation and drinking-water supply, flow into streams and lakes, and evaporation from areas with a shallow depth to groundwater.

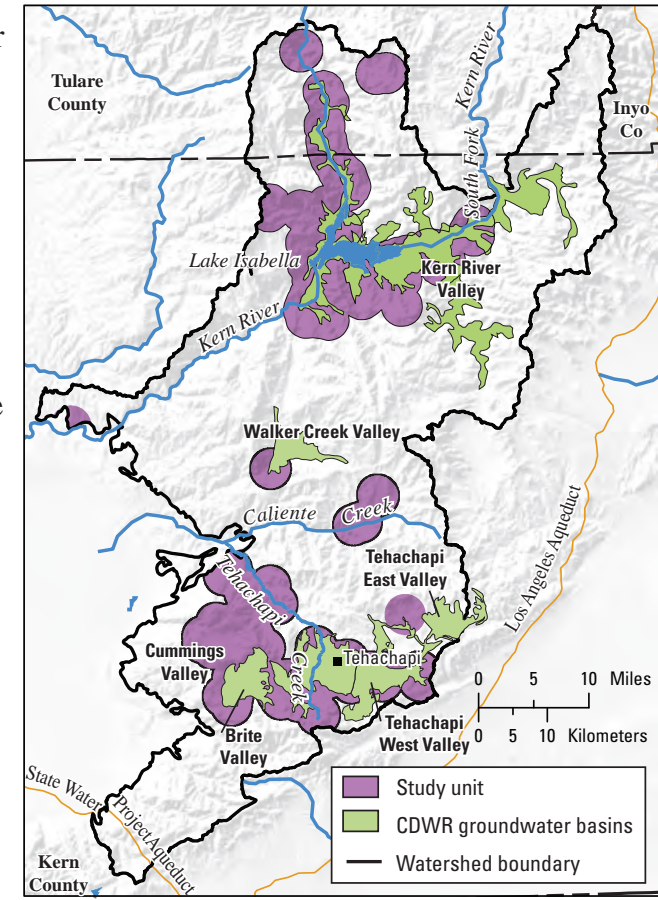

Overview of Water Quality

\section{Inorganic Constituents}

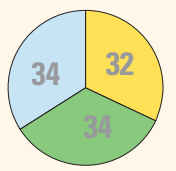

CONSTITUENT CONCENTRATIONS

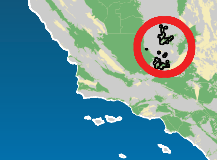

\section{Organic Constituents}

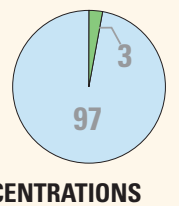

High $\bigcirc$ Moderate $\bigcirc$ Low or not detected

Values are a percentage of the area of the primary aquifers with concentrations in the three specified categories. Values on pie chart may not equal $\mathbf{1 0 0}$ due to rounding of percentages.

GAMA’s Priority Basin Project evaluates the quality of untreated groundwater. However, for context benchmarks established for drinkingwater quality are used for comparison. Benchmarks and definitions of high, moderate, and low concentrations are discussed in the inset box on page 3 .

Many inorganic constituents occur naturally in groundwater. The concentrations of the inorganic constituents can be affected by natural processes as well as by human activities. In the Southern Sierra Nevada study unit, one or more inorganic constituents were present at high concentrations in about 32\% of the primary aquifers and at moderate concentrations in about 34\%.

Human-made organic constituents are found in products used in the home, business, industry, and agriculture. Organic constituents can enter the environment through normal usage, spills, or improper disposal. In this study unit, one or more organic constituents were present at moderate concentrations in about $3 \%$ of the primary aquifers, and none were detected at high concentrations. 


\section{RESULTS: Groundwater Quality in the Southern Sierra Nevada Study Unit}

\section{INORGANIC CONSTITUENTS}

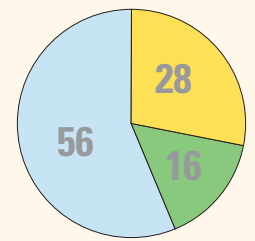

Trace

elements

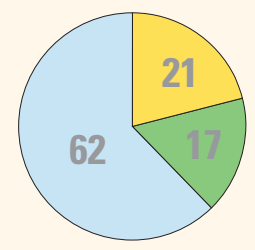

\section{Radioactive constituents}

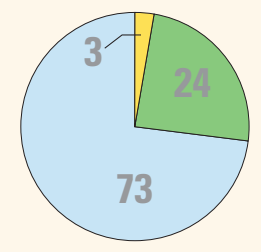

\section{Nutrients}
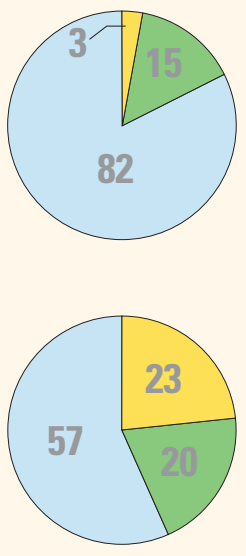

\section{Total Dissolved Solids}

\section{Manganese or iron}

\section{Inorganic Constituents with Human-Health Benchmarks}

Trace and minor elements are naturally present in the minerals in rocks and soils, and in the water that comes into contact with those materials. In the Southern Sierra Nevada study unit, trace and minor elements were present at high concentrations in about $28 \%$ of the primary aquifers, and at moderate concentrations in about $16 \%$. Arsenic, fluoride, and boron were the trace and minor elements that most frequently occurred at high and moderate concentrations. Aluminum and antimony also were detected at high concentrations, but in less than $(<) 1 \%$ of the primary aquifers.

Radioactivity is the emission of energy or particles during spontaneous decay of unstable atoms. Humans are exposed to small amounts of natural radioactivity every day. Most of the radioactivity in groundwater comes from decay of naturally occurring uranium and thorium in the rocks or sediments of the aquifers. Radioactive constituents occured at high levels in about $21 \%$ of the primary aquifers, and at moderate levels in about $17 \%$. Gross alpha particle, uranium, and radon-222 activities were the radioactive constituents that most frequently occurred at high and moderate levels.

Nutrients, such as nitrogen, are naturally present at low concentrations in groundwater. High and moderate concentrations generally occur as a result of human activities. Common sources of nutrients include fertilizer applied to crops and landscaping, seepage from septic systems, and human and animal waste. The nutrient nitrate was present at high concentrations in about $3 \%$ of the primary aquifers, and at moderate concentrations in about $24 \%$.

\section{Inorganic Constituents with Non-Health Benchmarks}

\section{SPECIAL-INTEREST CONSTITUENTS}

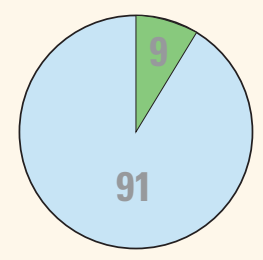

\section{Perchlorate}

(Not included in water-quality overview charts shown on the front page)

Some constituents affect the aesthetic properties of water, such as taste, color, and odor, or may create nuisance problems, such as staining and scaling. The State of water naturally contains TDS as a result of the weathering and dissolution of minerals in soils. Iron and manganese are naturally occurring constituents that commonly are present together in groundwater. Anoxic conditions in groundwater (very low amounts of dissolved oxygen) may result in release of manganese and iron from minerals into groundwater.

In the Southern Sierra Nevada study unit, TDS was present at high concentrations (greater than the upper limit) in about 3\% of the primary aquifers, and at moderate concentrations (between the recommended and upper limits) in about 15\% of the primary aquifers. Manganese and (or) iron, were present at high concentrations in about 23\% of the primary aquifers, and at moderate concentrations in about $20 \%$.

\section{Perchlorate}

(Not included in water-quality overview charts shown on the front page)

Perchlorate is an inorganic constituent that has been regulated in California drinking water since 2007. It is an ingredient in rocket fuel, fireworks, safety flares and other products, may be present in some fertilizers, and also occurs naturally at low concentrations in groundwater. Perchlorate was detected at moderate concentrations in about 9\% of the primary aquifers. California has a recommended and an upper limit for total dissolved solids (TDS). All 


\section{RESULTS: Groundwater Quality in the Southern Sierra Nevada Study Unit}

\section{ORGANIC CONSTITUENTS}

Solvents

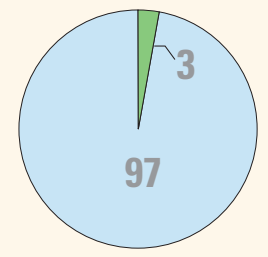

\section{Other volatile organic compounds}

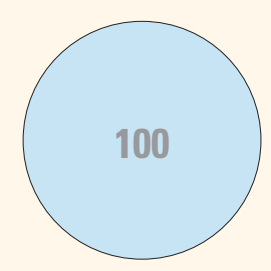

Pesticides

\section{Organic Constituents}

The Priority Basin Project uses laboratory methods that can detect the presence of low concentrations of volatile organic compounds (VOC) and pesticides, far below human-health benchmarks. VOCs and pesticides detected at these very low concentrations can be used to help trace water from the landscape into the aquifer system.

\section{Volatile Organic Compounds with Human-Health Benchmarks}

VOCs are in many household, commercial, industrial, and agricultural products, and are characterized by their tendency to volatilize (evaporate) into the air.

Solvents are used for a number of purposes, including manufacturing and cleaning. In the Southern Sierra Nevada study unit, solvents were not present at high concentrations in the primary aquifers. Solvents were present at moderate concentrations in about $3 \%$ of the primary aquifers, and at low concentrations (or not detected) in about $97 \%$.

Other VOCs include trihalomethanes, gasoline additives, refrigerants, and organic synthesis reagents. Trihalomethanes form during disinfection of water supplies, and may enter groundwater by the infiltration of landscape irrigation water or leakage of distribution lines. Gasoline additives increase the efficiency of fuel combustion. Other VOCs were not detected at high or moderate concentrations in the primary aquifers. Trihalomethanes, gasoline additives, and refrigerants were detected at low concentrations in the primary aquifers. Organic synthesis reagents were not detected.

\section{Pesticides with Human-Health Benchmarks}

Pesticides, including herbicides, insecticides, fungicides, and fumigants, are applied to crops, gardens, lawns, around buildings, and along roads to help control unwanted vegetation (weeds), insects, fungi, and other pests. In the Southern Sierra Nevada study unit, pesticides were not detected at high or moderate concentrations in the primary aquifers. Herbicides were detected at low concentrations. Organic synthesis reagents were not detected.

\section{BENCHMARKS FOR EVALUATING GROUNDWATER QUALITY}

GAMA’s Priority Basin Project uses benchmarks established for drinking water to provide context for evaluating the quality of untreated groundwater. After withdrawal, groundwater may be disinfected, filtered, mixed, and exposed to the atmosphere before being delivered to consumers. Federal and California regulatory benchmarks for protecting human health (Maximum Contaminant Level, MCL) were used when available. Nonregulatory benchmarks for protecting aesthetic properties, such as taste and odor (Secondary Maximum Contaminant Level, SMCL), and nonregulatory benchmarks for protecting human health (Notification Level, NL, and Lifetime Health Advisory, HAL) were used when Federal or California regulatory benchmarks were not available.

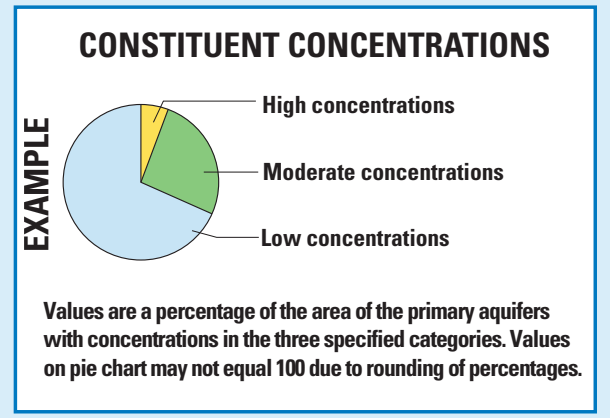

\section{High, moderate, and low concentrations are defined relative to benchmarks}

Concentrations are considered high if they are greater than a benchmark. For inorganic constituents, concentrations are moderate if they are greater than one-half of a benchmark. For organic constituents and perchlorate, concentrations are moderate if they are greater than one-tenth of a benchmark; this lower threshold was used because organic constituents generally are less prevalent and have smaller concentrations relative to benchmarks than inorganic constituents. Low values include non-detections and values less than moderate concentrations. Methods for evaluating water quality are discussed in Fram and Belitz (2012). 


\section{Factors that Affect Groundwater Quality}

In the Southern Sierra Nevada study unit, arsenic and uranium were two of the constituents most frequently present at high and moderate concentrations. The USEPA MCL for arsenic is 10 micrograms per liter and the California MCL for uranium is 20 picocuries per liter. Groundwater with high or moderate concentrations of arsenic or uranium was found more frequently in the Kern River Valley basin and surrounding watershed than in the Tehachapi-Cummings Valley basins and surrounding watershed. Dissolution of arsenic and uranium from minerals in the aquifer sediments or rocks requires appropriate groundwater geochemical conditions (such as $\mathrm{pH}$ and dissolved oxygen concentration), enough time for dissolution, and presence of minerals containing arsenic and uranium.

The ranges of groundwater geochemical conditions and ages were similar in the northern and southern parts of the study unit, suggesting that the chemical and mineralogical compositions of the aquifer materials in the north and south were different (Fram and Belitz, 2012). The granitic and metamorphic rocks in the north contain many more historical prospects and mines (primarily gold, tungsten, and uranium) than do the rocks in the south (U.S. Geological Survey, 2005). This suggests the rocks in the north naturally have greater abundances of these metals. Many metals, including gold, commonly occur with sulfide minerals that may contain arsenic. In addition to natural dissolution of metals from rocks into groundwater, disturbances caused by mining activities may increase the rate at which metals are dissolved.

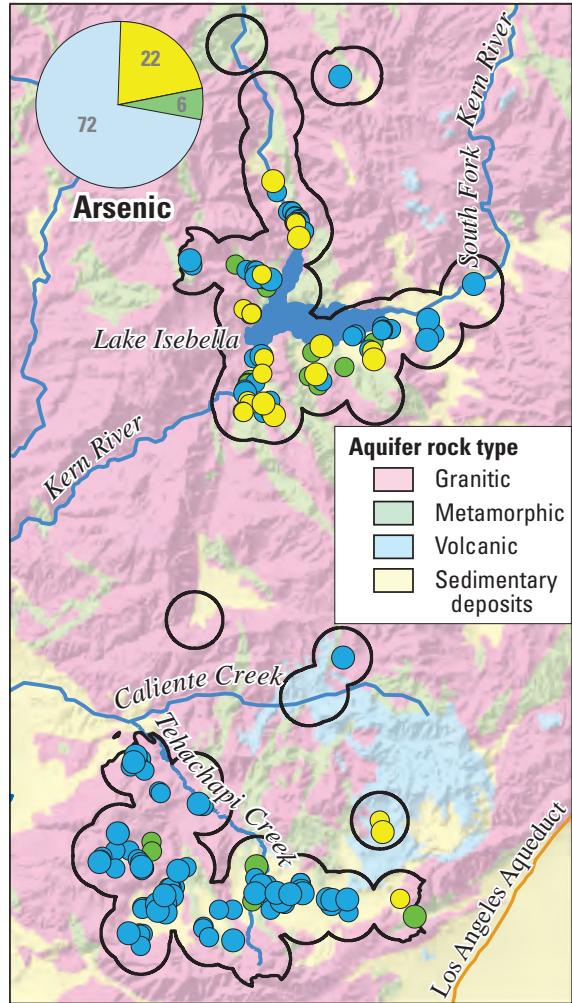

By Miranda S. Fram and Kenneth Belitz

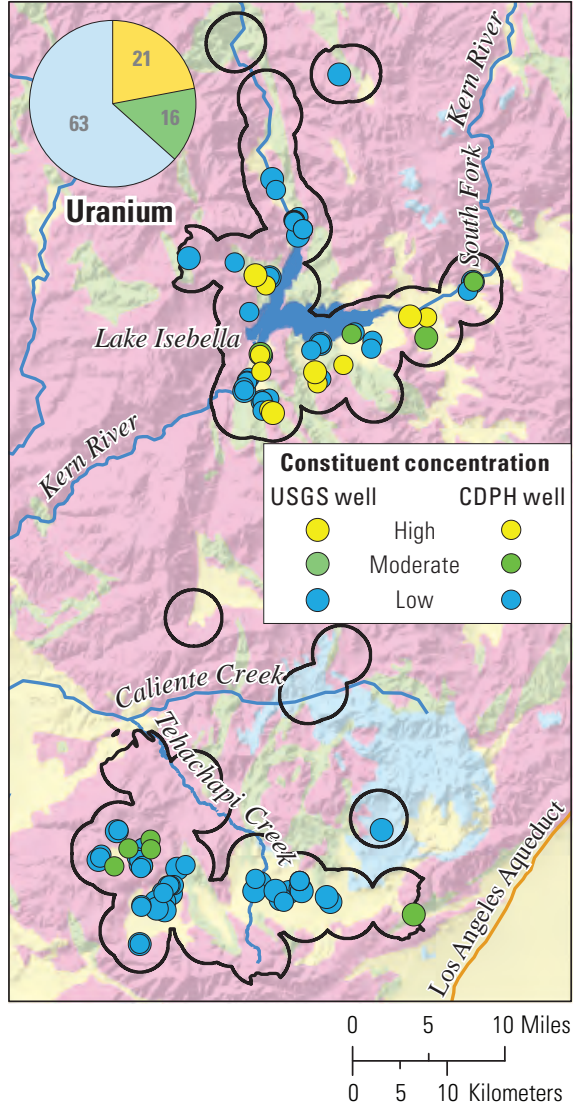

\section{SELECTED REFERENCES}

California Department of Water Resources, 2003, California's groundwater: California Department of Water Resources Bulletin 118, 246 p.http://www.water.ca.gov/aroundwater/bulletin118/update2003. $\mathrm{cfm}$.

Fram, M.S., and Belitz, Kenneth, 2007, Groundwater quality data in the Southern Sierra study unit, 2006: Results from the California GAMA Program: U.S. Geological Survey Data Series 301, 78 p. (Also available at $\underline{\mathrm{http}: / / \mathrm{pubs} . \mathrm{usgs.gov} / \mathrm{ds} / 301 / \text {.) }}$

Fram, M.S., and Belitz, Kenneth, 2012, Status and understanding of groundwater quality in the Tahoe-Martis, Central Sierra, and Southern Sierra study units, 2006-2007-California GAMA Program Priority Basin Project: U.S. Geological Survey Scientific Investigations Report 20115216, 222 p. (Also available at http://pubs.usqs.gov/sir/2011/5216.)

U.S. Geological Survey, 2005, Mineral Resources Data System: U.S. Geological Survey. http://tin. er.usgs.gov/mrds/

\section{Priority Basin Assessments}

GAMA's Priority Basin Project (PBP) assesses water quality in that part of the aquifer system used for drinking water, primarily public supply. Water quality in the primary aquifers, assessed by the PBP, may differ from that in the deeper parts of the aquifer, or from the shallower parts, which are being assessed by GAMA's Domestic Well Project. Ongoing assessments are being conducted in more than 120 basins throughout California.

The PBP assessments are based on a comparison of constituent concentrations in untreated groundwater with benchmarks established for protection of human health and for aesthetic concerns. The PBP does not evaluate the quality of drinking water delivered to consumers.

The PBP uses two scientific approaches for assessing groundwater quality. The first approach uses a network of wells to assess statistically the status of groundwater quality. The second approach combines water-quality, hydrologic, geographic, and other data to help assess the factors that affect water quality. In the Southern Sierra Nevada study unit, data were collected by the PBP in 2006, and from the CDPH database for 2003 - 2006. The PBP includes chemical analyses not generally available as part of regulatory compliance monitoring, including measurements at concentrations much lower than human-health benchmarks, and measurement of constituents that can be used to trace the sources and movement of groundwater.

\section{For more information}

Technical reports and hydrologic data collected for the GAMA PBP Program may be obtained from:

\section{GAMA Project Chief}

U.S. Geological Survey

California Water Science Center 4165 Spruance Road, Suite 200

San Diego, CA 92101

Telephone number: (619) 225-6100 WEB: http://ca.water.usgs.gov/gama

\section{GAMA Program Unit}

State Water Resources Control Board Division of Water Quality

PO Box 2231, Sacramento, CA 95812

Telephone number: (916) 341-5779 WEB: http://www.waterboards.ca.gov/gama 